\title{
Web application design for the control process of public schools
}

\author{
Carlos Daniel Mendoza-Santos ${ }^{1}$, Alexi Delgado ${ }^{2}$ \\ ${ }^{1}$ SystemsEngineeringProgram, Universidad de Ciencias y Humanidades, Lima-Peru, carmendozas@uch.pe \\ ${ }^{2}$ MiningEngineeringSection, Pontificia Universidad Católica del Perú, Lima-Peru, kdelgadov@ pucp.edu.pe
}

\begin{abstract}
The present research work was presented in the context of the deficit problematic in the inventory process of public schools in Peru. The main objective is for public schools to use ICTs to improve this process. The methodology used for the development of the research work is Scrum, since it allows the application model to be carried out in an agile and organized manner. The different needs that each stage of the methodology presented were solved by the Balsamiq Mockups tool. In the results we can appreciate that implementing this web system offers speed and security to the management of the inventory of the public schools, since it is necessary to have a control of all the goods in real time. Therefore, this paper can be useful to public school functionaries who wish to implement a logistics system such as the one that has been designed
\end{abstract}

Key words :Balsamiq Mockups, Inventory, Logistic, Scrum.

\section{INTRODUCTION}

The logistical process is decisive for any company, regardless of its field, since it allows them to manage an internal control that facilitates the location of products if necessary [1]. In Peru, however, the inventory process is difficult because there is no internal control, which means that there is a weakness in not having an inventory favored by the use of ICTs and personnel trained in handling the information [2]. This is aggravated in the regions, which are unaware of the adequate inventory control process because they do not have sufficient technology to be able to adequately control products [3]. The problem to be solved is the deficit in the inventory process that public schools currently have, not because it is the only context affected, but because we consider it to be the most urgent to address. Therefore, the present proposal is to implement an information system in which it is possible to have real time control and know the location of its products internally (a crucial need to be aware).

Different types of methodologies exist for the development of a technological system which permits to have the control of its goods in real time, among them UML, RUP, SCRUM and MVC. The UML methodology is a frequently used Objectives Management Group, and is one of the standard modeling languages widely used for object oriented design and documentation. UML provides 14 types of diagrams that can be used to describe a system from different points of view, which helps us manage more complex systems [4]. The RUP methodology uses an architecture that is case driven and incremental through development software, has a life cycle that contains four continuous phases: start, development, construction and transition, also has 9 workflows, which includes business modeling, requirements, analysis and design, implementation, testing, deployment, configuration and change management, project management and the environment [5]. Whereas Scrum is an agile and lightweight framework that allows us to manage and control the software and product development process, it also allows us to combine the iterative model and incremental model for constructions as they are successive and incremental in terms of the characteristics for developing software object orientation, this methodology was also designed to increase the speed of development [6]. On the other hand, finally, the MVC pattern is a software design pattern that is used to implement user interfaces. Effective use of the pattern as it separates logic resulting in an application that is easier to customize, has three components and are components of Model, View and Controller, which allows you to make web applications, as it is a universally accepted model, through several languages and implementation frameworks [7]. The methodology to be applied in the present work is the SCRUM methodology, since it has a structure that will allow us to have optimum control and will accelerate the development of the software.

In the application of this system it will be possible to have a control in real time of all the goods of the institution, as well as it will be possible to record its goods, the suppliers, the purchases made, in addition it will have the option to move the good according to the stock, to be able to visualize if it is in active state or of leave. Finally, there will also be indicators that will allow to appreciate the amount of purchases made per month and the amount of goods registered per month, as an added feature there will be an option to print reports of purchases, suppliers and goods registered [8].

The objective of this research project is for schools to use ICT (Information and Communication Technologies) to improve the management of the inventory process, in order to have real time control and avoid the continuous use of traditional methods such as the notebook or some sheets, as it has been happening. 
This work is structured as follows, in section II the methodology used for the design of the system will be described in further detail. Section III will illustrate the case study together with its application. In section IV we will discuss our findings and finally in section $\mathrm{V}$ we will show the conclusions of the project.

\section{METHODOLOGY}

The methodology to be used to perform the research work as well as the tools are:

\subsection{Prototype Development}

The prototypes development is to have a vision of how the system will be once implemented. The elaboration of the prototypes of this system is a beneficial resource since it allows to define the requirements of information by the users. The development of these prototypes has to be elaborated before each development of the system phase, in order to determinate the exact requirements that each development phase of a system can involve. Prototypes are mostly easy and fast to develop.

\subsection{Balsamiq Mockups}

It is an effective tool that allows you to create prototypes of systems or applications to be developed as quickly as possible with a user-friendly interface; it is one of the most commonly used tools for prototyping, as it has several components that adapt to the application to be developed.

\subsection{Scrum}

It is an incremental interactive framework for dynamic development of projects or applications. It has a development structure in cycles known as "Sprint", it can also be interpreted as a set of tasks that are organized to be completed in a certain time. These interactions have a time range of 1 to 4 weeks, and are occurring one after the other. Sprints have a precise duration, these have to end on a specific date, even if the work has not been completed, and do not have to be extended, because time is shortened. When you start a Sprint, a fine-functional team has to select the items (customer requirements) from a prioritized list [6].

Scrum has 5 very important phases that allow us to carry out projects in a more flexible way:

\section{A. Requirements gathering:}

This refers to the list of requirements that is delivered by the client, in the list is detailed everything that the client requires in its project.

\section{B. Backlog Management:}

It refers to the tasks that have to be carried out once the list of requirements delivered by the client has been achieved.

\section{Sprint Planning Meeting:}

It is the planning of the Sprint.

\section{Execution of Sprint:}

This execution is of those sprint already elaborated in the phase of planning, this execution has a maximum period of 2 to 4 weeks.

\section{E. Inspection and interaction:}

It is the revision and presentation of the sprint already finished by the group in charge.

In Figure 1, the phase diagram of the SCRUM methodology is shown together with the tools to be used for the development of the system.

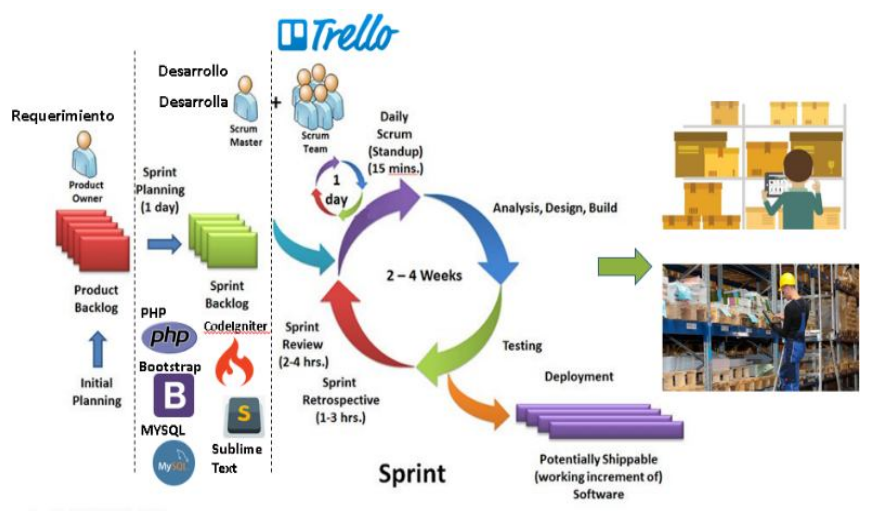

Figure 1: SCRUM methodology phase diagram along with the tools to be used for the development of the system

\section{APPLICATION}

\subsection{Application Architecture}

PHP provides a framework that aims to accelerate the process of developing a website. Nowadays, there are many programming oriented frameworks that use a full stack from model design to MVC (Model View Controller) design. The use of these designs, especially the MVC design, is to provide ease in the development of web applications. Writing code is more systematic and reusable. In addition, the use of framework greatly assists programmers in the development of large-scale applications that involve many people. With the framework, the code will be organized so that it can be easily understood by other programmers [9]. In Figure 2, the structure of the MVC pattern is shown as well as the functionality of each component.

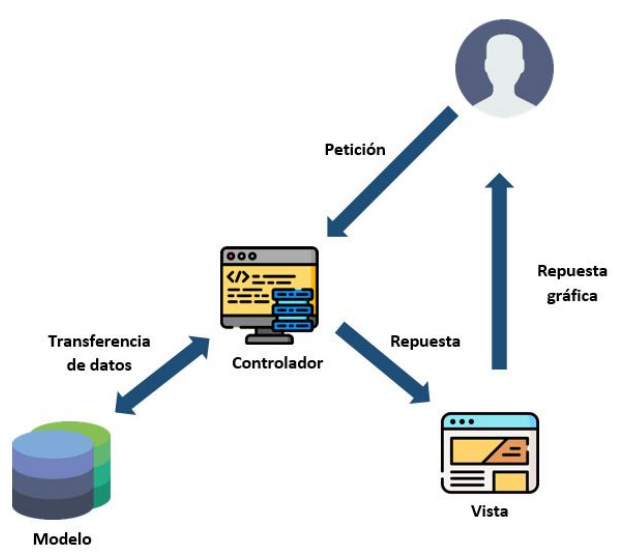

Figure 2: MVC pattern structure 


\subsection{Prototype Design}

The design of the web system was done with BalsamiqMockups with the purpose of automating the processes of the public school for a better visualization of account statement and payments of their debts avoiding generating doubts regarding incomes, obtaining exact values for decision making.

The application will be made so that public schools can have control of their goods and services in real time and thus stop using the traditional method of pencil and notebook.

\section{A. Requirements gathering:}

- As Administrator, there is a need to log into the system with a username and password in order to secure the account.

- As Registrator, it is necessary to enter the system with a username and password in order to secure the account.

- As Administrator, it is required to have access to the whole system, registration of categories, item, distribution, reports, indicators, users, permissions.

- As Registrator it is important to register the categories, item and distribution.

\section{B. Backlog Management:}

- Sprint Users: In this sprint all the respective maintenance to the user module and permissions will be performed. The person in charge of this module is the Administrator, since he is the one who has all the control of the system.

- Sprint Item: In this sprint all the respective maintenance to the module item and categories will be made. The person in charge of this module will be both the administrator and the registrator, since both will have access to the modules.

- Sprint Distribution: In this sprint all the respective maintenance to the distribution, active inventory and low module will be carried out. The person in charge of this module will be both the administrator and the registrator, since both will have access to the modules.

- Sprint Reports: In this sprint all the respective maintenance to the module of reports will be made. The person in charge of this module will be the administrator, since he is the one who has all the control of the system.

\section{Sprint Planning Meeting:}

This phase organizes all Sprints within a development chronogram, which details who is responsible for the project and how much time will be used for its development. In Figure 3, we can see a chronogram of system development activities by Sprint.

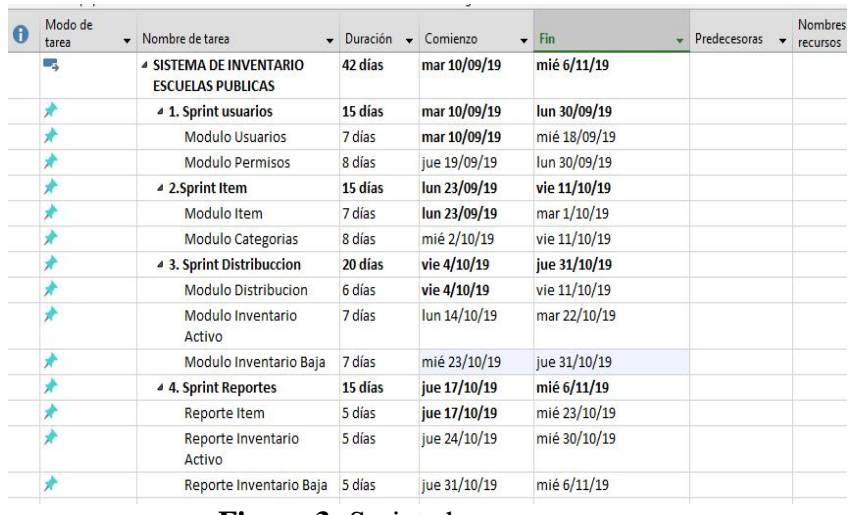

Figure 3: Sprint chronogram

\section{Execution of Sprint:}

- Sprint Users: Figure 4 and Figure 5 show the login and user module prototypes (which has the functions of listing, registering, modifying and deleting).

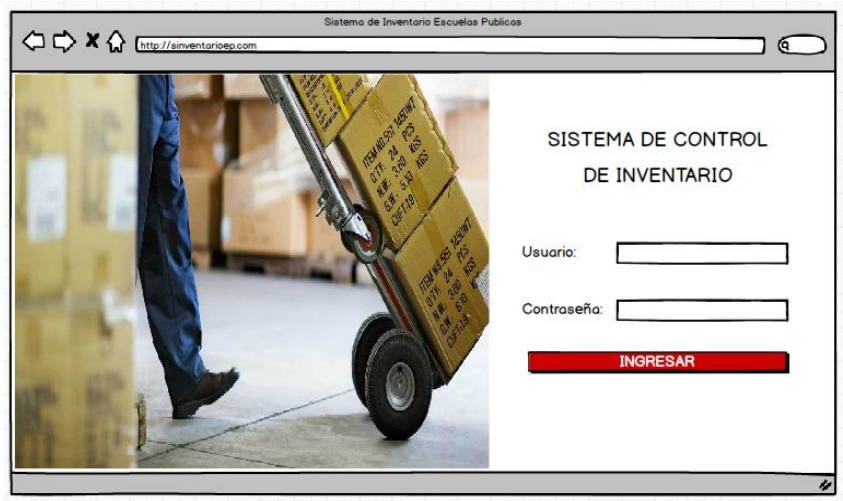

Figure 4: Login Prototype

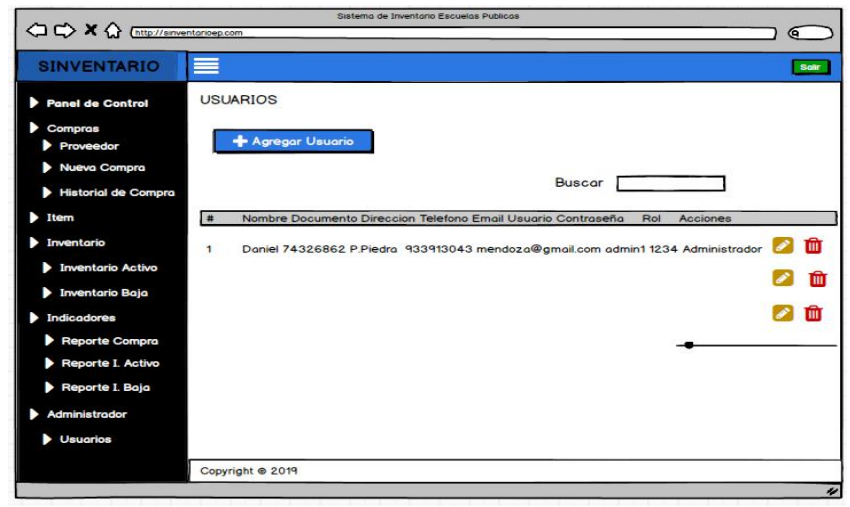

Figure 5: User Module Prototype

- Sprint Item: Figure 6 and Figure 7 show the prototypes of the item module (list, register, modify and delete) and of the categories module (list, register, modify and delete), respectively. 


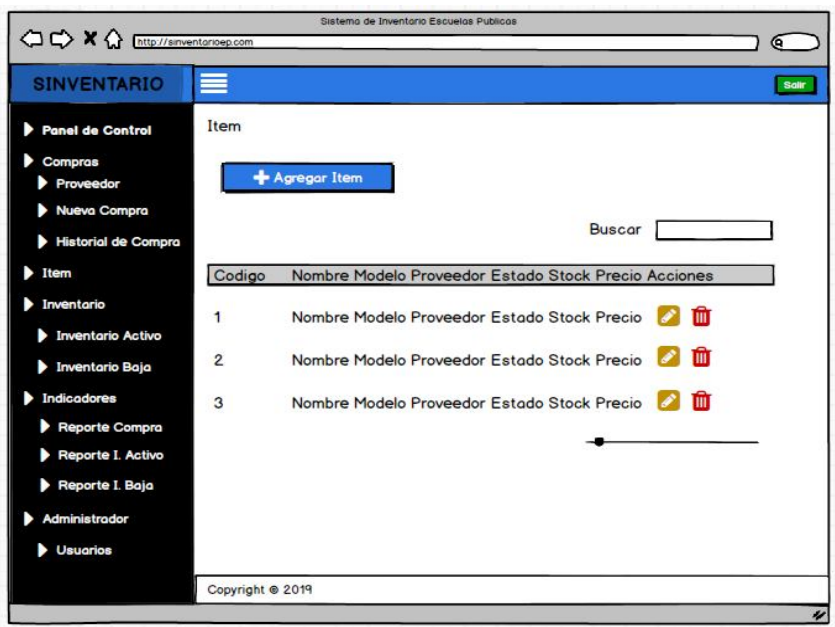

Figure 6: Item Module

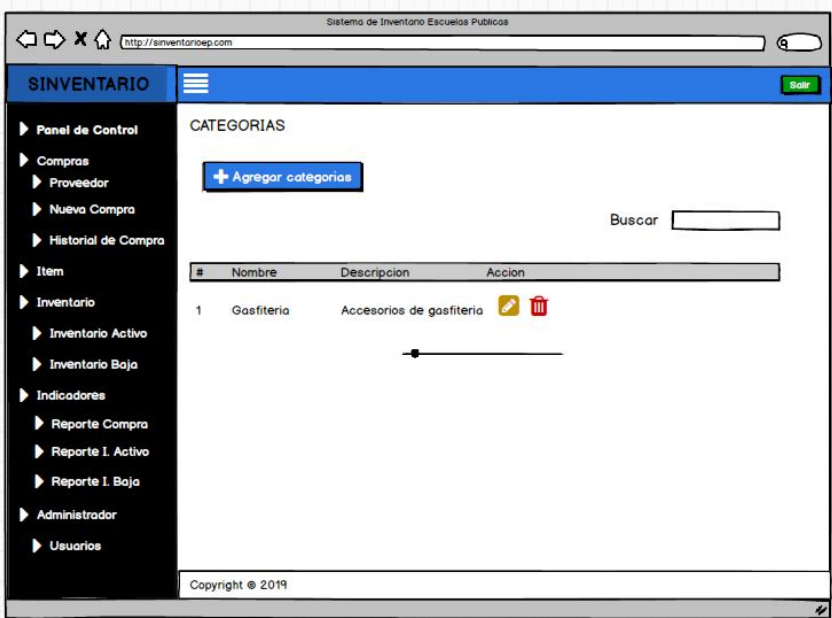

Figure 7: Categories Module

- Sprint Distribution: Figure 8 and Figure 9 show the prototypes of the active and low inventory module (list, edit and delete).

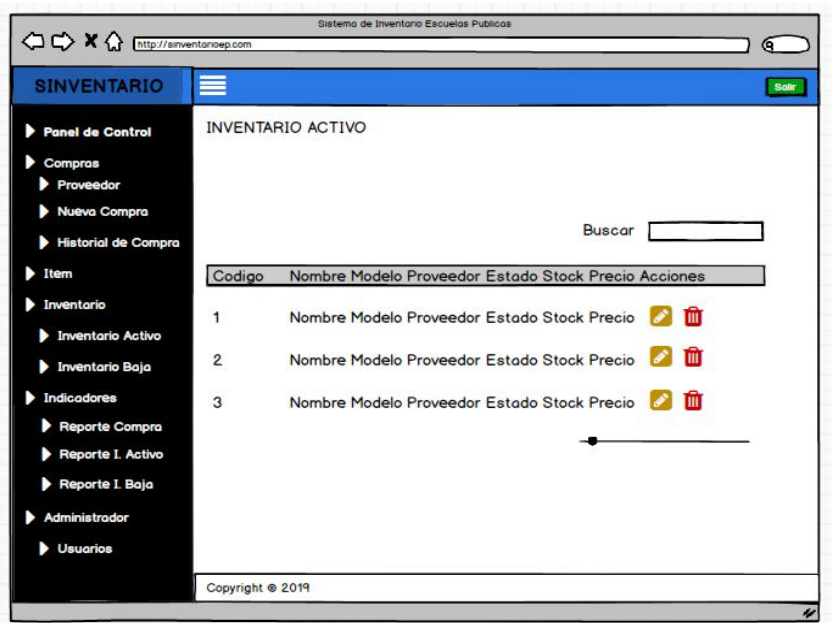

Figure 8: Active Inventory Module

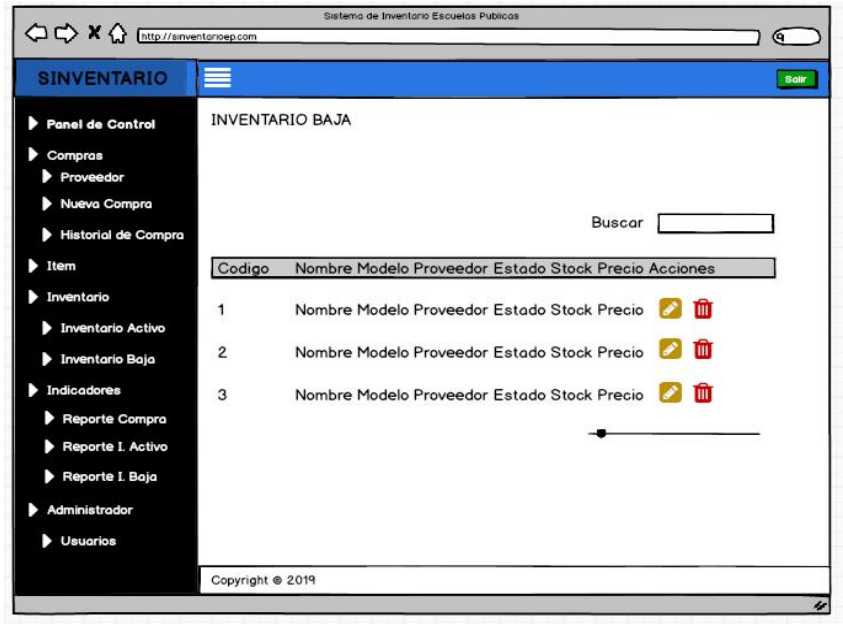

Figure 9: Low Inventory Module

- Sprint Reports: Figure 10 and Figure 11 show the prototypes of the active and low inventory reporting module with the option to print in formats such as Excel and PDF.

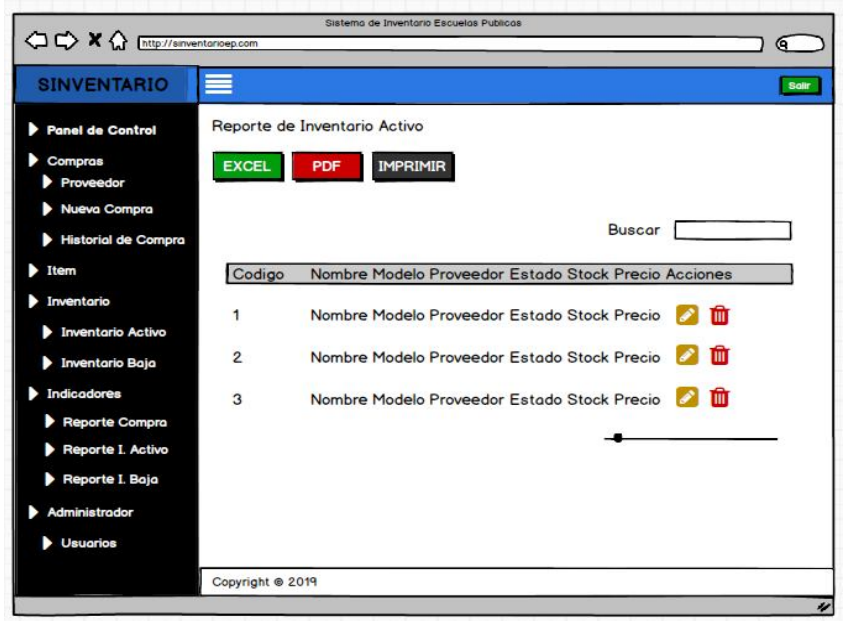

Figure 10: Active Inventory Report

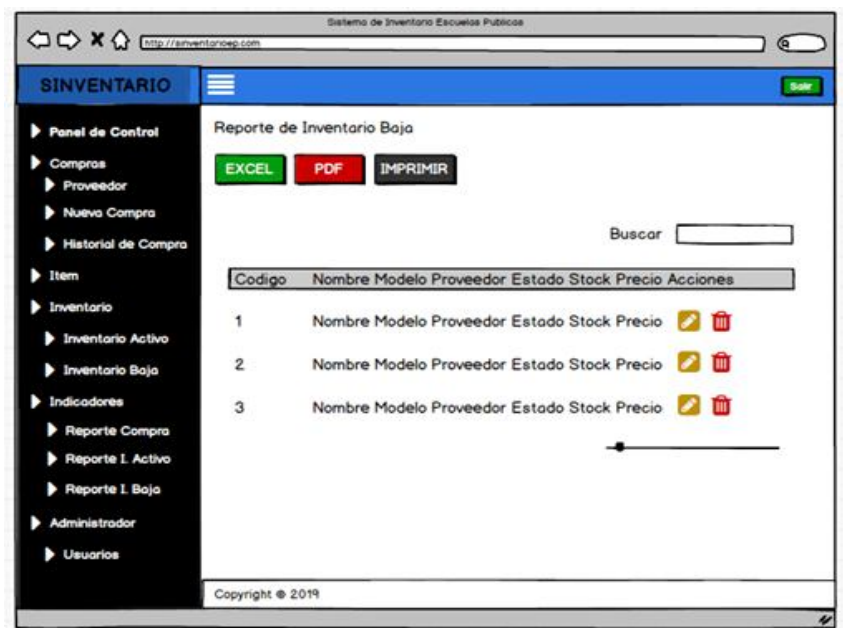

Figure 11: Low Inventory Report 


\section{E. Inspection and interaction:}

In this phase the Sprint are approved once finished, by means of the manipulation of the system the users will approve the development, it will be indicated to them that they have to register the data in each view carried out, the system will count with validations by field, this in order that it is allowed to register texts in data fields of texts and numbers in data fields of numbers, similarly the search of registered data will be with exact data.

\section{RESULTS AND DISCUSSION}

\subsection{About the Case Study}

This study responds to the immediate need to maintain optimal logistical control to recognize the location of the goods of Peru's public schools. The use of ICTs has been proposed through the design of the web system developed in the current study. This is an effective way of solving the problems observed, but it should also be mentioned that it is easy to use because it is user-friendly, which contributes greatly since this type of problem not only requires financing from the public sector (which, incidentally, is quite accessible), but also calls for new management methodologies [10].

On the other hand, regarding the tool there has been evaluated the paper elaborated by Soutome, Ling, Niibori and Kamada [11], who used a web tool for the development of their prototypes, Mockingbird, which is a web tool that allows to create prototypes by means of the placement of components of common use as buttons in the pages by means of the drag and drop operation [11].

The difference between Mockingbird and Balsamiq Mockup software is that the first is only a web service, whereas the second has a web service and a desktop service, both can create interactive prototypes of websites, mobile applications, etc., both have two ways of access, one is free and the other is a form of payment, a monthly membership that has to be made to be able to use all the components of each service in its entirety.

\subsection{About the Methodology}

\section{A. Advantages}

Scrum offers a personalized way of working on different projects that have a variety of requirements, as well as the flexibility it offers because no specific procedure has to be followed. Also, being widely used, Scrum can provide the possibility of joining together with other methodologies and/or tools [6].

\section{B. Disadvantages}

A disadvantage of Scrum is that team members may prefer to avoid certain vital steps to complete the sprint, in order to shorten the time of an unforeseen event.

\section{Comparison}

It has been evaluated that, to differences of other methodologies, Scrum allows us to have a more advanced control in the subject of the development of the system, this unlike methodologies like RUP and UML specifically [12], one of the differences that exists between Scrum and RUP is that whereas in RUP it does not exist what is a plan of project that begins and finishes, in Scrum there is which is denominated Sprint [13][14]. On the other hand, the differences between Scrum and UML are that the second is more a language of independent modeling of a development methodology, since it has to adapt to any methodology; whereas Scrum does not have to adapt to any methodology because it already is and allows us to carry out a more organized project and with a more agile form of development [15][16].

\section{CONCLUSION}

Finally, the objective was achieved, which was to create a prototype of the web application views to be developed in order to obtain an efficient logistics of resources in public schools in Peru. This was achieved by means of the Balsamiq Mockup tool, a tool that allowed us to carry out the project interactively and visualize it in a pre-developed way.

About the methodology used, Scrum enabled us to organize ourselves for the development of research, the development of prototypes and the requirements established within the web application.

In future research it would be recommended to develop the web application based on the prototypes made. It is also suggested that despite being a user-friendly web system, there should be a training that prepares workers effectively in order to avoid that this tool is used wrongly and there may be errors, or not be fully advantageous.

If you wish, you may write in the first person singular or plural and use the active voice ("I observed that ..." or "We observed that ..." instead of "It was observed that ..."). Remember to check spelling. If your native language is not English, please get a native English-speaking colleague to proofread your paper.

\section{REFERENCES}

1. A. Saltos-Vargas, C. Pita-Solarte, «Estándares De Procedimientos De Control De Inventarios En Arenera $X \& C$ Cía. Ltda. Inventory Control ProcedureStandards at Arenera X\&C Cia.», 2018.

2. C. L. Kong Sandoval, «Implementación de un sistema de inventarios y su efectos sobre las utilidades de la empresa HDTV Satelital S.A.C. Implementation of aninventorysystem and itseffectontheprofits of thecompany HDTV Satelital S.A.C», 2013.

3. G. Gutierrez, Diseño De Un Sistema Para El Control De Inventarios Para La Distribuidora “A\&L”. Design of an Inventory Control System for the "A\&L" Distributorship. 2015.

4. D. Torre, «On validating UML consistency rules», en 2015 IEEE International Symposium on Software 
Reliability Engineering Workshops, ISSREW 2015, 2016, pp. 59-60.

https://doi.org/10.1109/ISSREW.2015.7392041

5. L. Jin and X. Liang, «Modeling of instant messaging system based on RUP and UML», en Proceedings - 2016 International Conference on Computational Intelligence and Applications, ICCIA 2016, 2016, pp. 61-66.

https://doi.org/10.1109/ICCIA.2016.18

6. A. Srivastava, S. Bhardwaj, and S. Saraswat, «SCRUM model for agile methodology», en Proceeding - IEEE International Conference on Computing, Communication and Automation, ICCCA 2017, 2017, vol. 2017-January, pp. 864-869.

7. M.Jailia, A. Kumar, M. Agarwal, and I. Sinha, «Behavior of MVC (Model View Controller) based Web Application developed in PHP and.NET framework», en Proceedings of 2016 International Conference on ICT in Business, Industry, and Government, ICTBIG 2016, 2017.

8. F. Lestari, U. Ulfah, F. R. Aprianis, and S. Suherman, «Inventory Management Information System in Blood Transfusion Unit», en IEEE International Conference on Industrial Engineering and Engineering Management, 2019, vol. 2019-December, pp. 268-272.

https://doi.org/10.1109/IEEM.2018.8607557

9. U. Sa'Adah, J. Akhmad, and M. Hisyam, «Implementing Singleton method in design of MVC-based PHP framework», en Proceedings - 2015 International Electronics Symposium: Emerging Technology in Electronic and Information, IES 2015, 2016, pp. 212-217.

10. A. V. Kalinichenko, E. P.Javoronkov, E. L. Christenko, and T. L. Averianova, "Logistic management in public health», en 8th Korea-Russia International Symposium on Science and Technology - Proceedings: KORUS 2004, 2005, vol. 3, pp. 234-236.

11. T. Soutome, D. K. Ling, M. Niibori, and M. Kamada, «A web-based platform for clients and designers to prototype web sites», en Proceedings - 16th International Conference on Network-Based Information Systems, NBiS 2013, 2013, pp. 459-463.

12. L. Jin and X. Liang, "System modeling of vehicle management based on RUP and $U M L »$, en Proceedings 2012 5th International Symposium on Computational Intelligence and Design, ISCID 2012, 2012, vol. 1, pp. 53-56.

13. E. Braude, "Incremental UML for Agile Development: Embedding UML Class Models in Source Code», en Proceedings - 2017 IEEE/ACM 3rd International Workshop on Rapid Continuous Software Engineering, RCoSE 2017, 2017, pp. 27-31. https://doi.org/10.1109/RCoSE.2017.1

14. M. Sacasqui, J. Luyo, A. Delgado, «A Unified Index for Power Quality Assessment in Distributed Generation Systems Using Grey Clustering and Entropy Weight», in 2018 IEEE ANDESCON, ANDESCON 2018 Conference Proceedings, 2018, pp. 8564631.

15. V. T. Faniran, A. Badru, and N. Ajayi, «Adopting Scrum as an Agile approach in distributed software development: A review of literature», en 2017 1st International Conference on Next Generation Computing Applications, NextComp 2017, 2017, pp. 36-40.
16. A. Delgado, A. Aguirre, E. Palomino, G. Salazar, "Applying triangular whitenization weight functions to assess water quality of main affluents of Rimac river», in Proceedings of the 2017 Electronic Congress, E-CON UNI 2017, 2018, pp. 1-4. https://doi.org/10.1109/ECON.2017.8247308 